Rapid Reviews COVID-19

\title{
Reviews of "SARS-CoV-2 seroprevalence survey estimates are affected by anti-nucleocapsid antibody decline"
}

Samreen Zaidi, Roger Dodd ${ }^{1}$

${ }^{1}$ American Red Cross, Scientific Affairs, Medical Office, United States

Published on: Dec 04, 2020

DOI: $10.1162 / 2 \mathrm{e} 3983 f 5.353 \mathrm{c} 26 \mathrm{dc}$

License: Creative Commons Attribution 4.0 International License (CC-BY 4.0). 
To read the original manuscript, click the link above.

Summary of Reviews: This study cautiously asserts that the outcome of a seroprevalence study is impacted by the declining prevalence rate, which impacts the sensitivity. Reviewers suggest the conclusion is rational and largely justifiable but limited by the data they utilize.

\section{Reviewer 1 (Samreen Zaidi) | |}

Reviewer 2 (Roger Dodd)

$$
\begin{aligned}
& \text { RR:C19 Strength of Evidence Scale Key } \\
& \text { प्रमप = Misleading }
\end{aligned}
$$

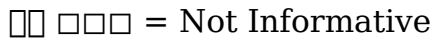

$$
\begin{aligned}
& \text { प्रा पि = Potentially Informative }
\end{aligned}
$$

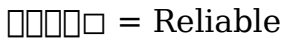

$$
\begin{aligned}
& \text { प्राप्र = Strong }
\end{aligned}
$$

To read the reviews, click the links below. 